\title{
DIFFERENTIATED EFFECT OF ADVERTISING: JOINT vS SEPARATE CONSUMPTION
}

\author{
Sangwon Park \\ Hospitality and Food Management \\ School of Hospitality and Tourism Management \\ University of Surrey \\ 53MS02 \\ Guildford, Surrey, GU2 7XH United Kingdom \\ e-mail: sangwon.park@ surrey.ac.uk \\ Juan L. Nicolau \\ Dpt. of Marketing \\ Faculty of Economics and Business Administration \\ University of Alicante \\ PO Box 99 \\ 03080 Alicante \\ Spain \\ e-mail: JL.Nicolau@ua.es
}




\title{
DIFFERENTIATED EFFECT OF ADVERTISING: JOINT vS SEPARATE CONSUMPTION
}

\begin{abstract}
In a context of intense competition, cooperative advertising between firms is critical. Accordingly, the objective of this article is to analyse the potential differentiated effect of advertising on two basic consumption patterns: individual products (i.e. hotel, restaurant) vs. bundle (i.e. hotel+restaurant). This research adds to the extant literature in that, for the first time, this potential differentiated effect is examined through a hierarchical modelling framework that reflects the way people make their decisions: first, they decide whether to visit or not a region; second, whether to purchase an advertised product in that region; and third, whether to buy products together or separately at the region. The empirical analysis, applied to a sample of 11,288 individuals, shows that the influence of advertising is positive for the decisions to visit and to purchase; however, when it comes to the joint or separate consumption, advertising has a differentiated effect: its impact is much greater on the joint alternative ("hotel+restaurant") than the separate options ("hotel" and "restaurant"). Also, the variable distance moderates the advertising effect.
\end{abstract}

Keywords: destination advertising; cooperative advertising; hierarchical decision making; random coefficient logit model. 


\section{INTRODUCTION}

Cooperative advertising has proven to be a central topic in the literature (Ahmadi-Javid \& Hoseinpour, 2012; Aust \& Buscher, 2012; 2014; Yang, Xie, Deng \& Xiong, 2012). Certainly, today's territorial competition to attract visitors is so fierce that marketing activities play a critical role in regional policies (Hamoudi \& Riseno, 2012; Barr, 2013). With the bottom-up approach, in which specific places within countries develop their own strategies to accomplish their own goals and implement their own promotional actions -rather than the countries themselves under the topdown approach- (Chien \& Gordon, 2008), it is justified the existing plethora of entities, both public and private, conducting myriads of actions in order to enhance their competitiveness. These actions can encompass a variety of activities, from the creation of leading-edge knowledge to gain competitiveness (Lambregts, 2008) to garner as much hype as possible through well thoughtthrough promotional strategies (Wöber \& Fesenmaier, 2004).

In this line, cooperative advertising shows collusive profit-maximizing decisions regarding advertising expenditures that might be found between different levels of the distribution system (e.g. hotels and tour operators) and within the same level (e.g. between hotels or between hotels and restaurants) (Aust \& Buscher, 2014). According to these authors, the former represents a vertical cooperative advertising strategy through which manufacturers and retailers share the advertising expenditures (beyond the obvious franchisor-franchisee example, this strategy has appeared in different contexts when the need to share costs is prevalent today); and the latter shows a horizontal cooperative advertising strategy in which competitors might join forces to promote specific categories of products rather than particular brands. Evidently, a manager eventually expects customers to opt for the firm's products, but the first step is to make them choose the category to which the product belongs. As explained latter, the results of this paper present relevant managerial implications for the horizontal cooperative advertising strategy. Note that in those regions where tourism-led development has become a central objective in their agenda, joint advertising emerges as a way to look for synergies (Biagi \& Detotto, 2012): not only do regional decision-makers want to know the regional economic impacts of tourism (Zhang, Madsen, \& Jensen-Butler, 2007) but also how to make people come to their destinations. Through promotional campaigns, regions attempt to become more appealing to potential visitors. However, with the economic recession, tourism demand, spending and employment have largely declined, which have made it challenging to get public funding for tourism advertising (Ritchie, Molinar, \& Frechtling, 
2010; Sheldon \& Dwyer, 2010). This situation certainly calls for a more efficient use of advertising budgets.

In this regard, it is important to note that most advertising studies that analyse the effect of regional promotional campaigns only consider a single type of travel decision, mainly destination choice, without considering the diverse products consumed at the destination (e.g., hotel, restaurants, rent cars and so on) (Wöber \& Fesenmaier, 2004), thereby discarding other decisions that can be relevant to the region.

More importantly, according to Polenske's (2004) analyses of cooperation and collaboration in a context of regional competition, destinations should not only try to compete against other destinations (through advertising campaigns, for example) but consider how their actions lead people to behave (their consumption patterns, for example) at the destinations themselves, which can shed light on potential collaborations regarding promotional activities among private firms at the destination. Note that, in line with the results of Beltran-Royo, Zhang, Blanco and Almagro (2013), a destination can be seen as "a firm with several products", where cross elasticities help optimize the advertising investment.

Along these lines, the objective of this article is to analyse the potential differentiated effect of regional advertising on two basic consumption patterns: individual products (i.e. hotel, restaurant) vs. bundle (i.e. hotel+restaurant). The travel consumption phenomenon is in line with the argument of multi-category decision making behaviour suggested by Russell et al. (1997) and Russell and Kamakura (1997). The multi-category decision making suggests that a single category choice behaviour predicts only a partial model of consumer behaviour and overlooks possible dependencies between the consumer's purchase outcomes across product categories. In a context of regional rivalry where investments in promotion are made, this article goes a step further and looks into the way these advertising investments have an influence on visitors' spending patterns. To this aim, and based on Jeng and Fesenmaier's (2002) contingent travel behaviour that tourism consumers have to make a variety of travel decisions (e.g., destination, accommodation, transportation, catering etc), and that the decisions made earlier condition the ones made in later stages, a hierarchical decision process is used so that the different impacts of destination advertising can be observed. 


\section{LITERATURE REVIEW}

\section{Multiple-Category Decision Making}

The advent of technology enables marketing researchers to obtain basket data that contain a wealth of information about consumer behaviour for product/service providers. This evolution allowed the researchers to develop choice models to explain purchasing results including store choice, incidence, brand choice, and quantity (Seetharaman, et al., 2005). Based upon these research streams, a series of research articles have been published with entitling Multi-Category Decision Making; for example, Boztuğ and Hildebrandt (2008), Russell and Petersen (2000), Russell and Kamakura (1997), Russell, et al. (1999), Seetharaman, et al (2005). The multi-category decision making suggests that in various settings, consumer choice involves the selection of a collection of products from different categories. As such, a consumer decision model that focuses on a single category choice behaviour provides the limited aspect of consumer behaviour in that the lack of concerning possible buying combinations between the consumer's purchase outcomes across product categories may cause a biased understanding of the determinants of consumer choices in the product category (Russell, et al., 1997). In contrary, a multi-category model aims to specify a full model of consumer behaviour, which offers a better understanding of consumer choices (Seetharaman, et al., 2005).

Russell et al. (1997) defined that multiple category choice as the selection of a collection of category choices for a given set of category alternatives. They proposed key characteristics of multiple category choice: (1) no substitution between elements of the collection and (2) interdependent utility of choices in other categories. More specifically, in a variety of settings, consumers are confronted with a situation where they can pick up any choices including alternatives from a subset of available categories which indicates limited substitution between elements. Also, since utility of product consumption depends on an appropriate match between other related products, the utility associated with one part of the bundle may be influenced by the utility of another part of bundle. This study argues that these two features of multiple category choice are consistent with the characteristics of tourism product, in terms of a multistage hierarchical trip decision net model proposed by Fesenmaier and Jeng (2000), Jeng and Fesenmaier (2002), and Nicolau and Más (2008). The decision net model implies that travellers (i.e., consumers in tourism) need to make a variety of decisions (e.g., destinations, hotels, restaurants, shopping, activities etc.) which may be purchased in different decision making stage (i.e., no substitution 
between elements of collection). Importantly, the model indicates that these travel decisions are interrelated by which the decisions made in previous stage influence ones of later stage (i.e., interdependent utility of choices) (Park, Wang, \& Fesenmaier, 2011).

Many marketing studies about multiple category choice modelling have been conducted within four different aspects of consumer purchasing decisions, such as incidence, store choice, brand choice, and quantity (Seetharaman, et al., 2005). Of them, this study mainly emphasizes the incidence aspect and in particular, models for 'Whether to Buy' (e.g., hotel and restaurant separately or simultaneously). A consumer's incidence decisions are associated across the features of products as the product characteristics serve as complements or substitutes in addressing the consumer's consumption needs as well as product categories challenge each other in attracting the consumer's limited spending budget. A number of consumer behaviour researchers have used various methods to better understand the purchasing behaviour. For example, Manchanda, Ansari, and Gupta (1999) and Chib, Seetharaman, and Strijnev (2002) conducted the multivariate probit model with the panel data to analyse household-level contemporaneous incidence outcomes in multi-product categories. Following them, Ma and Seetharaman (2004) employed multivariate logit model that considers six products, in order to estimate households' incidence outcomes. They indicated the suitability of the multivariate logit model whereby it shows an intrinsic propensity for any pair of product categories to co-occur within a household's shopping basket (Russell \& Peterson, 2000). More recently, Boztuğ and Hildebrandt (2008) suggested that a discrete choice model based on the multinomial logit model including sophisticated developments is the most suitable approach to modelling joint purchases. Thus, this study argues that it is imperative for estimating tourism advertising effectiveness to consider the hierarchical stages of the travel decision making process with multi-category consumption behaviour.

\section{Tourism Advertising Effectiveness}

Advertising has been explored in three different viewpoints such as persuasive, informative, and complementary aspects (Bagwell, 2005). Of them, informative view has been mainly discussed in advertising economic for several decades. For example, Stigler (1961) proposed a model concerning consumer's information search behaviour and identified that advertising reduces consumer's search costs by transmitting relevant information to potential and current consumers. That is, the informative advertising delivers clear and direct product information as to location, 
prices, functions, features, or benefits of products to consumers (King, et al., 1987). The idea of the informative advertising is providing credible information rather than persuading consumers or reminding them of the product advertised. Klein (1998) argues that products regarded as experience goods (i.e., i.e., before purchasing a good, the exact quality of the product cannot be assessed by the advertising information: travel products) can become search goods (i.e., before purchasing a good, the quality of the product can be estimated by the advertising information) when advertising offers critical and useful information to consumers prior to making a decision to purchase the products. In particular, people can build indirect experience from diverse advertising information content and stimulus such as text, images, and videos. That is to say, the risk inherent in product choice can be greatly reduced as consumers gain increased knowledge about the available alternatives (Bettman \& Park, 1980).

On account of the characteristics of travel products (i.e., intangible, perishable, heterogeneous and inseparable), travellers are actively involved in searching for information in order to reduce the high level of perceived uncertainty and risk (Roehl \& Fesenmaier, 1992; Gursoy \& McCleary, 2004). In this vein, tourism advertising is regarded as one of the main external information and communication sources (Morgan \& Pritchard, 2001; Wicks \& Schuett, 1991). Some evidence suggests that compelling advertising messages consciously and unconsciously affect consumers' trip decisions (Martin, 2010). Woodside and his colleagues point out the importance of tourism marketing and related service marketing (especially, destination advertising) in travel decisions and behaviours, based on the assumption that travel choice behaviour includes linear cause-and-effect relationships with marketing variables in general, and advertising in particular (e.g., Woodside \& King, 2001; Woodside \& MacDonald, 1994; Woodside, McDonald, \& Trappey, 1997).

Various approaches have been developed to estimate the tourism advertising effectiveness based upon the assumption that developing well-structured evaluation procedures are imperative for destination marketers to contribute the organization's ongoing planning and management processes. Conversion study has been largely employed as a dominant approach to assessing tourism advertising campaigns through which the proportion of people who requested and/or inquired information is compared with actual destination visitors and trip expenditure generated from the advertising fulfilment (Hunt \& Dalton 1983). The underlying assumption of the conversion study is sequential/linear steps; the awareness of tourism advertising leads to the 
positive image of destination and then, the positive image causes inquiry information which in turn influences conversion behaviour (Burke \& Gitelson, 1990). However, methodological deficiencies including sampling techniques, nonresponse bias, the time of which the advertising affects travellers' decision making (i.e., before or after decision making process), and failure containing all costs associated for advertising have been largely criticized (Ellerbrock, 1981).

With the understanding drawbacks of the conversion study, a number of researchers have suggested other methodologies/techniques to analyse advertising effectiveness such as advertising tracking study (Siegel \& Ziff-Levine, 1990), true-quasi experiment (Mok, 1990), cross-sectional analysis (Beldona, Morrison, \& Ismail, 2003), travel cost method (Silberman \& Klock 1986), econometric modelling (ButterField, et al. 1998). Kim, Hwang and Fesenmaier (2005) proposed an expanded framework to tourism advertising effectiveness. This study suggested the importance of considering psychological states such as cognitive and behavioural processes, which indicate the sequential advertising response process. That is, consumers who have seen tourism advertising create cognitive responses (i.e., Top-of-Mind, Advertising Awareness, and Requesting Information) and in turn, these psychological factors influence travel decision making.

However, these advertising studies in tourism have focused on a partial facet of travel choice behaviour (mainly, destination choice), with a lack of recognition that travel is a complex process. Jeng and Fesenmaier (2002) stated that travel decision making processes are sequential, hierarchical and multistage contingent. That is, travellers are required to consider a variety of decisions/facets interrelated, including primary destinations as well as accommodation, attractions, restaurants, and so on (Fesenmaier \& Jeng, 2000). Additionally, travel decision making encompasses a hierarchical process (Fesenmaier \& Jeng, 2000). Travellers are more likely to decide on their destination in the early stage and then products being consumed at the destination would be determined accordingly (e.g., accommodation, restaurants). Recently, Stienmetz, Maxcy, and Fesenmaier (2013) proposed facet-based advertising model and estimated the effect of travellers' responses to the advertising for each facet on total trip expenditure. However, the model includes lack of concerning the hierarchical process as well as the multi-category decisions. Based upon these previous findings, it is argued that the tourism advertising effectiveness model should be developed by concerning a hierarchical decision making process which enable advertising researchers to estimate varied effects of travel advertising on different types of tourism consumption behaviours. 
Concretely, the following three-stage process is proposed: first, visit a destination; second, purchase products featured in an advertisement; and third, buy specific types of advertised products (separately or together during the same stay at a destination). More specifically, once a traveller decides to visit the destination, he/she considers purchasing tourism products featured in the advertising (second stage). Further, this study proposes that travellers who decide to buy the advertised items implicitly purchase either single (e.g., hotels or restaurants) or products in a bundle (e.g., both hotels and restaurants) at the destination (third stage). Note that the first two decisions might be typical decisions studied in the literature on advertising influence. The third one, however, presents the novelty of being analysed while included in a hierarchical decision process to examine the advertising influence. The bundling strategy has always been a common strategy in tourism. Today, this relevance is even greater as the individual can self-build the combination of complementary travel products on his/her own (Beldona et al., 2005). In this regard, it is crucial to know the effect of advertising on people willingness to opt for a combination of tourism products vs. the alternative of purchasing individual products.

\section{Research Purposes}

This study first analyses the advertising influence on the consumption decision to purchase advertised "hotel" and "restaurants" separately or together, through its direct impact as well as with its interaction with travel distance. The inclusion of the interaction is justified as follows: heterogeneity in the effect of advertising informativeness might exert different degrees of influence. Consequently, this heterogeneity is taken into account through the variable distance. Contrary to traditional consumer purchasing behaviour, in which advertising and consumption typically occur in the same geographic locale, travel purchasing is consumed outside the consumer's usual environment where s/he is exposed to advertising (Baggio, et al., 2009). It is surprising, however, that despite the importance of distance in travel decision making, when it comes to the estimation of tourism advertising effectiveness only a limited number of studies have taken physical distance into account. For example, Silberman and Klock (1986) find that as distance increases, the advertising effect diminishes. Therefore, this variable is introduced into the model to control for its possible effect on the advertising influence.

Next, this research attempts to analyse different travel, information search and demographic characteristics among three travel purchasing groups who indicate different consumption patterns. 
Park, et al. (2011) found out that people who show different purchasing patterns (i.e., number and types of tourism products purchased) indicate not only different types of purchasing products, but also different intrinsic characteristics of individual consumers (i.e., demographic, travel planning, information search and Internet related variables).

\section{RESEARCH DESIGN}

\section{Data Analysis}

This section discusses a methodology for estimating the differentiated effects of advertising on the distinct stages of the tourist decision process: "whether to visit", "whether to purchase advertised items at the destination" and "what combination of advertised items to purchase: accommodation and restaurants separately vs. together". A Random Coefficient Multinomial Logit (RCL) model estimates this three-stage model. Specifically, RCL models are an alternative to the

more traditional multinomial logit models due to (Train, 2009): i) their ability to deal with the unobserved heterogeneity of consumers, by assuming that the coefficients of the variables vary among consumers; and ii) their flexibility, which allows representation of different correlation patterns among alternatives.

With regard to the first point, the whole consumer sample is unlikely to have the same set of parameter values. This variability implies the need to consider unobserved heterogeneity of individuals in parameter estimations. Hence, the utility of alternative $i$ for consumer $t$ is defined as $U_{i t}=X_{i t} \beta_{t}+\varepsilon_{i t}$ where $X_{i t}$ is a vector that represents the attributes of the alternative and the characteristics of consumers; $\beta_{t}$ is the vector of coefficients of these attributes and characteristics for each individual $t$, which represent personal tastes; and $\varepsilon_{i t}$ is a random term that is iid extreme value. This specification of the RCL model allows coefficients $\beta_{t}$ to vary over decision makers with density $g(\beta)$, which means that it differs from the traditional logit model in which $\beta$ is fixed. Thus, the non-conditional probability is the integral of $P_{t}\left(i / \beta_{t}\right)$ over all the possible values of $\beta_{t}$ :

$$
P_{i}=\int_{\beta_{t}} \frac{\exp \left\{\sum_{h=1}^{H} x_{i h} \beta_{t h}\right\}}{\sum_{j=1}^{J} \exp \left\{\sum_{h=1}^{H} x_{j h} \beta_{t h}\right\}} g\left(\beta_{t} \mid \theta\right) d \beta_{t}
$$


where $J$ is the number of alternatives and $g$ is the density function of $\beta_{t}$ and $\theta$ are the parameters of this distribution (mean and variance). Remember that a significant estimation of variance implies the superiority of the Multinomial Logit Model with random coefficients over the Multinomial Logit Model, due to non-compliance with IIA and to the ability to capture heterogeneity (Train, 2009).

However, the above integral does not give a closed solution, which means that its estimation requires the application of simulation techniques (Train, 2001). The final aim is to optimize the following maximum simulated likelihood function:

$$
\operatorname{MSL}(\theta)=\sum_{t=1}^{T} \sum_{j=1}^{J} d_{t j} \ln \left\{\frac{1}{R} \sum_{r=1}^{R} \frac{\exp \left\{\sum_{h=1}^{H} \beta_{t h}^{r} z_{i h}\right\}}{\sum_{j=1}^{J} \exp \left\{\sum_{h=1}^{H} \beta_{t h}^{r} z_{j h}\right\}}\right\}
$$

where $d_{t j}=1$ if individual $t$ chooses alternative $j$, and zero if not; and $R$ is the number of draws of the density function $\phi\left(\beta_{t}\right)$. In this case, vector $\theta=\{b, W\}$ represents the maximum simulated likelihood estimator (MSLE).

With regard to the second aspect, the flexibility of the RCL model allows us to represent different correlation patterns among non-independent alternatives. This flexibility avoids the assumption of Independence from Irrelevant Alternatives (IIA). Conversely, the multinomial logit model assumes the hypothesis of IIA, which supposes the existence of identical correlation patterns and, therefore, proportional substitutions across alternatives. In fact, the RCL model does not have the restrictive substitution patterns of the logit model, as the ratio of probabilities $P_{t i} / P_{t j}$ depends on all the data, including the attributes of alternatives other than $i$ and $j$. The flexibility of the RCL model also allows representation of any random utility model (McFadden \& Train 2000). In particular, an RCL model can approximate a Nested Logit (NL), which is appropriate for nonindependent and nested choice alternatives. Following Browstone and Train (1999), the RCL model is analogous to an NL model in that it groups the alternatives into nests by including a dummy variable in the utility function which indicates which nest an alternative belongs to. The presence of a common random parameter for alternatives in the same nest allows us to obtain a covariance matrix with elements distinct from zero outside the diagonal, obtaining a similar correlation pattern to that of an LN model. The Gauss program is used to estimate the model. In 
order to address second research purpose, Chi-square and ANOVA were used to compare the differences of demographic, information search and travel behaviour variables between travellers who show different purchasing patterns (e.g., booking just hotel, just restaurant and both hotel and restaurant).

\section{Sample, Data and Variables}

To reach the proposed objectives, the empirical application uses information on tourist choice behaviour obtained from a survey conducted on American travellers who had requested travel-related information from eighteen states in the U.S. during the 2010 season. More specifically, these people contacted official tourism destination websites or a specific tourism operator (e.g. VacationFun.com) to order tourism brochures containing information about travel products at the specific destinations (e.g., hotels, restaurants, activities etc.). The web-based survey was distributed to all inquirers according to the date of contact (within 3 months of the request for travel information). It was an online survey with a structured questionnaire and directed at a sample (over 18 years old) obtained in origin, which avoids the characteristic selection bias of destination collected samples and leads to a more precise analysis of tourist demand as it includes not only those people who travel and purchase but also those who do not. The original sample was of 13,074 individuals, and after controlling for missing values, the final sample size is of 11,288.

In order to make the choice models operative, this study define the variables used and identify the dependent and independent variables. 1) Dependent variable. To represent the set of alternatives available to the tourist, categorical variables are used to represent the decisions to visit/not-visit, to purchase an advertised/non-advertised item and to purchase a combination vs. separate products. For example, the survey asked the respondents to indicate their actual purchasing behaviours across multi-facets of the trip given the visit to the advertised destinations.

2) Independent Variable. i) Perception of advertising influence. This variable is obtained through a 5-point Likert scale (e.g., 5 = 'A lot of influence' to $1=$ 'No influence') by asking the individuals how much the travel information influences their travel plans. ii) Distance. The distance from the place of residence to the destination is measured by using three dummy variables to describe whether the destination is in the same state as the individual's home, in an adjacent state or an outer state. The in-state category is taken as the base reference. 
For group comparison, respondents were asked to answer regarding travel and Internet related questions including purpose of trip (i.e., vacation/getaway, special event, business/meeting, visit family/friends, and other), length of trip (i.e., less than one day, $1-2$ days, $3-4$ days, 5 or more days), party size (i.e., one person, two persons, 3 - 5 persons, 6 or more persons), and travel budget (from $\$ 0$ to $\$ 3,000$ or more) for travel behaviours, and Internet access (i.e., yes or no) and usage of website to collect travel information using 5-point Likert scale (e.g., almost every pleasure trip, most of the time, many times, sometimes, and almost never) for online information search behaviour.

\section{RESULTS}

Table 1 shows the results of the different models estimated. In general, this study indicates that the influence of advertising is positive for the decisions to visit and to purchase: for the visit decision, the variable "advertising influence" is positive and significant, meaning that advertising exerts a positive influence on the decision to visit a destination, in line with Woodside (1990). For the purchase decision, the variable "advertising influence" is positive and significant, thus advertising positively affects the decision to purchase services at the destination, in line with Gillespie and Morrison (2001).

However, the key result of this empirical application that gives response to the purpose of the article is the following: for the third decision "consumption combination" of tourism products, advertising has a differentiated effect. In particular, observe that its impact is much greater on the alternative "hotel+restaurant" than the separate options ("hotel" and "restaurant"). Specifically, only the alternative "hotel+restaurant" presents a positive and significant parameter.

Besides, given that the "hotel+restaurant" alternative shows significant heterogeneity in the effect of advertising, it means that there is room to further explain the factors that might determine this heterogeneity. As a first attempt to capture this heterogeneity, the variable distance is used. In this regard, and to provide a comprehensive overview of the moderating effect of distance, the three types of decisions are analysed: Regarding the decision to visit, the variables "adjacent" and "outer" states show negative and significant parameters in such a way that the further the destination is, the positive effect of advertising on the decision to visit becomes lower and lower. This result is in accordance with Messmer and Johnson (1993). In the purchase decision note, however, that the variable "adjacent state" is not significant and the variable "outer state" is positive 
and significant; these results represent a difference with the decision to visit. That is, while the more distant the destination is, the lower the advertising effect is, for the decision to purchase services at the destination, advertising always has the same positive effect in the case of adjacent states, and more positive effects in the case of "outer states". In other words, while the influence of advertising reduces as the region is located further away, its effect becomes more positive when it comes to purchasing products at a long-distance destination. Finally, concerning the "joint vs separate" consumption, the variables "adjacent" and "outer" states show positive and significant parameters for the "hotel+restaurant" alternative; therefore, the further the people are, the more effect advertising has on their decision to purchase a joint combination. Note that for the individual products, the variables related to the alternative restaurant have negative and significant parameters, and for the alternative hotel, only the variable "adjacent state" has a significant and positive parameter. Therefore, the effect of advertising is not only positive to attract people to a region but also, and most importantly for the purpose of this study, to make people purchase a bundle of products at the destination -rather than individual and separate products-.

[Insert Table 1 here]

Table 2 and 3 present the statistical results of group comparisons between different consumption behaviours. Travellers who tend to perform joint consumption are relatively higher income $\left(25.5 \%\right.$ over $\left.\$ 100,000 ; \chi^{2}=21.95, p<.01\right)$ than ones who just book hotel $(18.8 \%)$ and just restaurant (19.9\%). In terms of travel behaviours, travellers who bought both hotel and restaurant after exposure to advertising are likely to have more business trip $\left(6.2 \% ; \chi^{2}=179.89, p<.001\right)$ and less special event purpose $(9.8 \%)$, longer trip duration $\left(63.7 \%\right.$ over 3 days; $\chi^{2}=330.13, p<$ $.001)$, larger group compositions $\left(41.7 \%\right.$ over 3 persons; $\left.\chi^{2}=20.48, p<.001\right)$ and spend more travel budget $\left(32.6 \%\right.$ over $\left.\$ 1,000 ; \chi^{2}=294.05, p<.001\right)$ than other two purchasing groups. In addition, the joint purchasing travellers are more likely to use the Internet (77.5\% in Internet access; $\chi^{2}=53.68, p<.001 \&$ Mean $=4.32$ in usage of website; $\left.\mathrm{F}=3.21, p<.05\right)$ than other groups. Furthermore, travellers who just purchased hotel tended to go their trips for vacation/getaway $(61.6 \%)$, stay longer (51.4\% over 3 days) and slightly search more information online $(66.1 \%$ \& $\mathrm{M}=4.32$ ) than ones who purchase just restaurant $(40.6 \%, 58.4 \%$, and $\mathrm{M}=4.26$, respectively). 
[Insert Table 2 and 3 here]

\section{CONCLUSIONS}

The fact that the bundling/joint purchasing behaviour is a prevalent strategy in tourism can lead to design cooperative and collaborative actions among actors at a region. This prevalence is even greater on account of the capabilities that new technologies give to consumers: the individual can selfbuild the combination of complementary travel products on his/her own. Also important nowadays, with the current economic recession, it is imperative for tourism marketing organizations to comprehensively understand and estimate the advertising effects on travel decision making behaviours. Tourism researchers have found that travel decision making consists of multi-decisions or facets which form a hierarchical process. Nevertheless, most regional advertising studies focus on a main decision, destination choice. This study attempts to fill this research gap by employing multi-category decision making model suggesting that considering a single type of product causes a limited understanding of travel purchasing behaviour; rather, travellers tend to buy a number and variety of products during consumption process. In particular, this purchasing pattern is more relevant and generous in the tourism context. Thus, this article analyses the effect of advertising on people's willingness to opt for a combination of tourism products vs. the alternative of purchasing individual products by assuming a staged decision process: first, they decide whether to visit or not a destination; second, whether to purchase an advertised product; and third, whether to buy a joint combination of products vs. separate products. To achieve the research goal, RCL Models are applied with the assumption that travellers are heterogeneous and flexible in their decision making.

This research finds out that advertising has a differentiated effect on the "consumed together" and "consumed separately" tourism products. In particular, it is identified that the effect of advertising is much greater on the alternative "hotel+restaurant" than their separate options ("hotel" and "restaurant"). Also, heterogeneity in advertising influence is found, which is confirmed by the significant interactions detected through the variable distance. Furthermore, it is identified that people who show different consumption patterns between separate and joint purchasing behaviours reveal different demographic, travel and information search behaviours. Travellers who tend to make joint purchasing are more likely to use the Internet when planning their trip and take trips with the 
business purpose, longer length of stay at the destination, make more travel spending, and consist of a larger travel composition than those who tend to make separate product purchase.

With regard to practical implications, these findings can be important for destination marketers, according to the following points: i) The fact that the impact of advertising is much greater on the alternative "hotel+restaurant" than the separate options ("hotel" and "restaurant") favours a joint advertising strategy. That is, while the destination marketing organizations might be in charge of the promotion of the region, the firms at the region should be willing to cooperate and collaborate with the regional entity as well as with the other private firms when it comes to the design of the advertising strategy. Actually, only the joint consumption seems to be affected by advertising. Therefore, it is important to reach agreements with different components of tourism services at destinations, as the synergies obtained leverage advertising investments; ii) Interestingly, the positive effect of advertising on the joint consumption is enhanced when the region is further away from the individual's origin. It means that the destination marketers that attempt to attract people from other places should consider the variable distance as it seems to moderate the effect of advertising. Accordingly, at these places, the emphasis on cooperation and collaboration should be strengthened as the final impact of advertising is greater.

Regarding the theoretical implication, stand out: i) the hierarchical advertising model allows regional decision-makers to observe the degree of advertising influence in the different decisions proposed, as they can allocate more efficiently the available monetary resources for advertising because they can observe the decisions that are more influenced compared to others; and ii) the flexibility of the modelling approach used allows us to identify differentiated patterns of variables. For example, in the empirical application it is found that for the decision to visit, the more distant the destination, the lower the advertising effect, but for the decision to purchase services the reverse applies. This information would allow regional decision-makers to implement appropriate strategies on account of these types of differentiated patterns of variables.

The main limitation of the empirical application is the use of a limited number of explanatory variables. Note that the alternatives are defined in an abstract way (no specific brands are used, but types of decisions: whether the product bought was advertised or not, or whether it was bought in a bundle or separately). Therefore, this does not make it easy to find attributes for the alternatives. While the influence of advertising is the main variable and the focus of the analysis (i.e. the differentiated influence of advertising on different alternatives), as an attempt to 
complement the utility function, this study has resorted to an additional variable available to these abstract alternatives, which is the distance between the individual's origin and the destination chosen. 


\section{REFERENCES}

Ahmadi-Javid, A. \& Hoseinpour, P. (2012). On a cooperative advertising model for a supply chain with one manufacturer and one retailer. European Journal of Operational Research, 219(2), 458-466.

Aust, G., \& Buscher, U. (2012). Vertical cooperative advertising and pricing decisions in a manufacturer-retailer supply chain: A game-theoretic approach. European Journal of Operational Research, 223(2), 473-482.

Aust, G., \& Buscher, U. (2014). Cooperative advertising models in supply chain management: A review", European Journal of Operational Research, 234(1), 1-14.

Baggio, R., Cooper, C., Scott, N., \& Corigliano, M. A. (2009). Advertising and Word of Mouth in Tourism, A Simulation Study. In A. Fyall, M. Kozak, L. Andreu, J. Gnoth \& S. S. Lebe (Eds.), Marketing Innovations for Sustainable Destinations (pp. 13-22). Oxford, UK: Goodfellow PublishersBagwell, K. (2005), "The Economic Analysis of Advertising," Department of Economics, Columbia University.

Bagwell, K. (2005). The Economic Analysis of Advertising, Discussion Paper No.: 0506-01 Department of Economics, Columbia University.

Barr, J. (2013). Skyscrapers and skylines: New York and Chicago, 1885-2007. Journal of Regional Science, 53(3), 369-391.

Beldona, S., Morrison, A. M., \& Ismail, J. (2003). The impact of Internet usage charcteristics on online travel behavior. Advances in Hospitality and Tourism Research, 8, 22-28.

Beldona, S., Morrison, A. M., \& J. O’Learly. (2005). Online shopping motivations and pleasure travel products: A correspondence analysis. Tourism Management, 26, 561-570.

Beltran-Royo, C., Zhang, H., Blanco, L. A. \& Almagro, J. (2013). Multistage multiproduct advertising budgeting. European Journal of Operational Research, 225(1), 179-188.

Bettman, J. R., \& Park, W. C. (1980). Effects of prior knowledge and experience on consumer decision processes: A protocol analysis. Journal of Consumer Research, 7, 234-248.

Biagi, B. \& C. Detotto. (2012). Crime as tourism externality. Regional Studies, pages 1-17, DOI: $10.1080 / 00343404.2011 .649005$.

Boztuğ, Y., \& Hildebrandt, L. (2008). Modelling joint purchases with a multivariate MNL Approach. Schmalenbach Business Review, 60, 400-422.

Browstone, D., \& Train, K. (1999). Forecasting new product penetration with flexible substitution patterns. Journal of Econometrics, 89, 109-129.

Burke, J. F. \& Gitelson, R. (1990). Conversion studies: Assumptions, applications, accuracy and Abuse. Journal of Travel Research, 28(3), 46-51.

Butterfield, D. W., Deal, K. R., \& Kubursi, A.A. (1998). Measuring the returns to tourism Advertising. Journal of Travel Research, 37, 12-20.

Chib, S., Seetharaman, P. B., \& Strijnev, S. (2002). Analysis of multi-category purchase incidence decisions using IRI market basket data, in Philip Hans Franses and Alan L. Montgomery (eds.), Econometric Models in Marketing, Vol. 16, Amsterdam: Elsevier, 57-92.

Chien, S. S., \& Gordon, I. (2008). Territorial competition in China and the West. Regional Studies, 42(1), 31-49.

Ellerbrock, D. (1981). Improving coupon conversion studies. Journal of Travel Research, 19(4), 37-38.

Fesenmaier, D. R., \& Jeng, J. (2000). Assessing structure in the pleasure trip planning process. Tourism Analysis, 5, 13-27. 
Gillespie, C. \& Morrison, A. (2001). Commercial hospitality consumption as a live marketing communication system. International Journal of Contemporary Hospitality Management, 13(4), $183-188$.

Gursoy, D. \& McCleary. K.W. (2004). An integrative model of tourist's information search behaviour. Annals of Tourism Research, 31(2), 353-373.

Hamoudi, H. \& Risueno, M. (2012). The effects of zoning in spatial competition. Journal of Regional Science, 52(2), 361-374.

Hunt, J. D., \& Dalton, M. J. (1983). Comparing mail and telephone for conducting coupon conversion studies. Journal of Travel Research, 21, 16-18.

Jeng, J., \& Fesenmaier, D. R. (2002). Conceptualizing the travel decision-making hierarchy: A review of recent developments. Tourism Analysis, 7(1), 15-32.

Kim, D-Y., Hwang, Y-H., \& Fesenmaier, D. R. (2005). Modeling tourism advertising effectiveness. Journal of Travel Research, 44(1), 42-49.

King, K.W., Reid, L. N., Tinkham, S. F., \& Pokrywczynski, J. (1987). The perceived informativeness of national and retail advertising. Current Issues \& Research in Advertising, 10(1-2), 173-197.

Klein, L. R. (1998). Evaluating the potential of interactive media through a new lens: Search versus experience goods. Journal of Business Research, 41, 195-203.

Lambregts, B. (2008). Geographies of knowledge formation in mega-city regions: Some evidence from the Dutch Randstad. Regional Studies, 42(8), 1173-1186.

Ma, Y., \& Seetharaman, P. B. (2004). The Multivariate Logit Model for Multicategory Purchase Incidence Outcomes, Working Paper, Rice University.

Manchanda, P. Ansari, A., \& Gupta, S. (1999). The Shopping Basket: A model for Multicategory Purchase Incidence Decisions. Marketing Science, 18, 95-114.

Martin D. (2010). Uncovering unconscious memories and myths for understanding international tourism behaviour. Journal of Business Research, 63, 372-383.

McFadden, D., \& Train, K. (2000). Mixed MNL models of discrete response. Journal of Applied Econometrics, 15, 447-470.

Messmer, D. J., \& Johnson, R. R. (1993). Inquiry conversion and travel advertising effectiveness. Journal of Travel Research, 31(4), 14-21.

Mok, H. M. (1990). A quasi-experimental measure of effectiveness of destinational advertising: Some evidence from Hawaii. Journal of Travel Research, 29(1), 30-34.

Morgan, N., \& Pritchard, A. (2001). Advertising in tourism and leisure. Oxford: ButterworthHeinemann.

Nicolau, J. L., \& Más, F. J. (2008). Sequential choice behaviour: Going on vacation and type of destination. Tourism Management, 29, 1023-1034.

Park, S., Wang, D., \& Fesenmaier, D. R (2011). Assessing structure in American online purchase of travel products. Anatolia: An International Journal of Tourism and Hospitality Research, 22, 401-417.

Polenske, K. (2004). Competition, collaboration and cooperation: An uneasy triangle in networks of firms and regions. Regional Studies, 38(9), 1029-1043.

Ritchie, J. R. B., Molinar, C. M. A., \& Frechtling, D. C. (2010). Impacts of the world recession and economic crisis on tourism: North America. Journal of Travel Research, 49(1), 5-15.

Roehl, W. \& Fesenmaier, D. R. (1992). Risk perceptions and pleasure travel: An exploratory analysis. Journal of Travel Research, 30, 17-26.

Russell, G. J., Bell, D., Bodapati, A., Brown, C. L., Chiang, J., Gaeth, G., Gupta, S., \& Manchanda. P. (1997). Perspectives on multiple category choice. Marketing Letters, 8, 297-305. 
Russell, G. J., \& Kamakura, W.A. (1997). Modelling multiple category brand with household basket data. Journal of Retailing, 73, 439-461.

Russell, G. J., \& Petersen, A. (2000). Analysis of cross category dependence in market basket selection. Journal of Retailing, 76, 367-392.

Russell, G. J., Ratneshwar, S., Shocker, A.D., Bell, D., Bodapati, A., Degeratu, A., Hildebrandt, L., Kim, N., Ramaswami, S., \& Shankar, V. H. (1999). Multi-category decision-making: Review and synthesis. Marketing Letters, 10, 319-332.

Seetharaman, P. B., Chib, S., Ainslie, A., Boatwright, P., Chan, T., Gupta, S., Mehta, N., Rao V., $\&$ Strijnev, A. (2005). Models of multi-category choice behaviour. Marketing Letters, 16, 239-254.

Sheldon, P., \& Dwyer, L. (2010). The global financial crisis and tourism: Perspectives of the academy. Journal of Travel Research, 49(1), 3-4.

Siegel, W. \& Ziff-Levine, W. (1990). Evaluating tourism advertising campaigns: Conversion vs. advertising tracking studies. Journal of Travel Research, 28(3), 51-55.

Silberman, J. \& Klock, M. (1986). An alternative to conversion studies for measuring the impact of travel ads. Journal of Travel Research, 28, 12-16.

Stienmetz, J. L., Maxcy, J. G., \& Fesenmaier, D. R. (2013). Evaluating destination advertising. Journal of Travel Research, forthcoming.

Stigler, G. (1961). The economics of information. Journal of Political Economy, 69, 213-225.

Train, K. E. (2001). Halton Sequences for Mixed Logit. Working paper, University of California, Berkeley.

Train, K. E. (2009). Discrete Choice Methods with Simulation, Nueva York: Cambridge University Press.

Wicks, B.E. \& Schuett, M. A. (1991). Examining the role of tourism promotion through the use of brochures. Tourism Management, 12(4), 301-312.

Wöber, K., \& Fesenmaier, D. R. (2004). A multi-criteria approach to destination benchmarking: A case study of state tourism advertising programs in the United States. Journal of Travel and Tourism Marketing, 16(2/3), 1-18.

Woodside, A. G. (1990). Measuring advertising effectiveness in destination marketing strategies. Journal of Travel Research, 29(2), 3-8.

Woodside, A.G. \& King, R. I. (20010. An updated model of travel and tourism purchaseconsumption systems. Journal of Travel and Tourism Marketing, 10(1), 3-27.

Woodside, A. G., McDonald, R. M., \& Trappey, R. J. (1997). Measuring linkage-advertising effects on customer behaviour and net revenue. Canadian Journal of Administrative Sciences, 14(2), 214-228.

Woodside, A., \& R. MacDonald. (1994). General System Framework of Customer Choice Processes of Tourism Services. In R. Gasser, \& K. Weiermair (Eds.), Spoil for choice: Decision-making processes and preference changes of tourists - Intertemporal and intercountry perspectives. Thaur, Austria: Kulturverlag.

Yang, J., Xie, J., Deng, X., \& Xiong, H. (2012). Cooperative advertising in a distribution channel with fairness concerns. European Journal of Operational Research, 227(2), 401-407.

Zhang, J., Madsen, B., \& Jensen-Butler, C. (2007).Regional economic impacts of tourism: The Case of Denmark. Regional Studies, 41(6), 839-854. 
Table 1

Models with "income, age and distance" for the decisions "Hotel", "Restaurant" and "H \& R"

(Standard error in parenthesis)

\begin{tabular}{|c|c|c|c|}
\hline \multirow[b]{2}{*}{ Variables } & \multicolumn{3}{|c|}{ Models with distance } \\
\hline & Hotel & Rest. & H \& R \\
\hline Influence $_{\text {(visit decision) }}$ & $\begin{array}{l}0.928^{\mathrm{a}} \\
(0.041)\end{array}$ & $\begin{array}{l}0.912^{\mathrm{a}} \\
(0.042)\end{array}$ & $\begin{array}{l}0.924^{\mathrm{a}} \\
(0.041)\end{array}$ \\
\hline Influence $_{\text {(purchase decision) }}$ & $\begin{array}{l}0.436^{\mathrm{a}} \\
(0.033)\end{array}$ & $\begin{array}{l}0.492^{\mathrm{a}} \\
(0.038)\end{array}$ & $\begin{array}{l}0.338^{\mathrm{a}} \\
(0.034)\end{array}$ \\
\hline Influence $_{\text {(joint vs. separate) }}$ & $\begin{array}{l}-0.140 \\
(0.155)\end{array}$ & $\begin{array}{l}-0.324^{\mathrm{a}} \\
(0.090)\end{array}$ & $\begin{array}{l}0.184^{\mathrm{a}} \\
(0.054)\end{array}$ \\
\hline $\mathrm{SD}_{\text {[influence (joint vs. separate)] }}$ & $\begin{array}{l}0.121 \\
(0.230) \\
\end{array}$ & $\begin{array}{l}0.465^{\mathrm{a}} \\
(0.141) \\
\end{array}$ & $\begin{array}{l}0.181^{\mathrm{a}} \\
(0.052)\end{array}$ \\
\hline $\operatorname{Adj~} \mathrm{x}$ infl (visit decision) $_{\text {(n) }}$ & $\begin{array}{l}-0.747^{a} \\
(0.032)\end{array}$ & $\begin{array}{l}-0.742^{\mathrm{a}} \\
(0.032)\end{array}$ & $\begin{array}{l}-0.746^{\mathrm{a}} \\
(0.031)\end{array}$ \\
\hline Out $\mathrm{x}$ infl $\mathrm{l}_{\text {(visit decision) }}$ & $\begin{array}{l}-1.158^{a} \\
(0.032)\end{array}$ & $\begin{array}{l}-1.154^{\mathrm{a}} \\
(0.032)\end{array}$ & $\begin{array}{l}-1.157^{\mathrm{a}} \\
(0.032)\end{array}$ \\
\hline Adj $x$ infl (purchase decision) & $\begin{array}{l}0.042^{\mathrm{c}} \\
(0.019)\end{array}$ & $\begin{array}{l}0.104^{a} \\
(0.021)\end{array}$ & $\begin{array}{l}0.033 \\
(0.020)\end{array}$ \\
\hline Out $\mathrm{x}$ infl $\mathrm{l}_{\text {(purchase decision) }}$ & $\begin{array}{l}0.118^{\mathrm{a}} \\
(0.022)\end{array}$ & $\begin{array}{l}0.168^{\mathrm{a}} \\
(0.024)\end{array}$ & $\begin{array}{l}0.089^{\mathrm{a}} \\
(0.024)\end{array}$ \\
\hline Adj $x$ infl (joint vs. separate) & $\begin{array}{l}0.084^{b} \\
(0.031)\end{array}$ & $\begin{array}{l}-0.183^{\mathrm{a}} \\
(0.051)\end{array}$ & $\begin{array}{l}0.056^{\mathrm{c}} \\
(0.024)\end{array}$ \\
\hline Out $\mathrm{x}$ infl (joint vs. separate) & $\begin{array}{l}0.020 \\
(0.037) \\
\end{array}$ & $\begin{array}{l}-0.240^{b} \\
(0.085)\end{array}$ & $\begin{array}{l}0.068^{\mathrm{c}} \\
(0.028) \\
\end{array}$ \\
\hline Constant $_{\text {(visit decision) }}$ & $\begin{array}{l}-1.184^{a} \\
(0.089)\end{array}$ & $\begin{array}{l}-1.149^{a} \\
(0.090)\end{array}$ & $\begin{array}{l}-1.175^{\mathrm{a}} \\
(0.089)\end{array}$ \\
\hline Constant $_{\text {(purchase decision) }}$ & $\begin{array}{l}-2.056^{a} \\
(0.109)\end{array}$ & $\begin{array}{l}-2.834^{a} \\
(0.127)\end{array}$ & $\begin{array}{l}-1.979^{a} \\
(0.113)\end{array}$ \\
\hline Constant $_{\text {(joint vs. separate) }}$ & $\begin{array}{l}-0.700^{c} \\
(0.279)\end{array}$ & $\begin{array}{l}1.485^{a} \\
(0.173)\end{array}$ & $\begin{array}{l}-0.723^{\mathrm{a}} \\
(0.159)\end{array}$ \\
\hline
\end{tabular}

$\mathrm{a}=$ prob $<0.1 \% ; \mathrm{b}=$ prob $<1 \% ; \mathrm{c}=$ prob $<5 \%$. 
Table 2

Demographic differences between travel purchasing groups

\begin{tabular}{lllll}
\hline & Just Hotel & $\begin{array}{c}\text { Just } \\
\text { Restaurant }\end{array}$ & $\begin{array}{c}\text { Hotel and } \\
\text { Restaurant }\end{array}$ & Chi-Square \\
\hline $\begin{array}{l}\text { Demographic } \\
\text { Annual income }\end{array}$ & & & $21.95^{* *}$ \\
$\quad$ Less than $\$ 50,000$ & $20.6 \%$ & $23.8 \%$ & $19.9 \%$ & \\
$\$ 50,001-\$ 75,000$ & $33.3 \%$ & $30.2 \%$ & $29.0 \%$ & \\
$\$ 75,001-\$ 100,000$ & $27.3 \%$ & $26.0 \%$ & $25.6 \%$ & \\
$\$ 100,001-\$ 125,000$ & $12.4 \%$ & $12.8 \%$ & $17.1 \%$ & \\
$\$ 125,000$ or more & $6.4 \%$ & $7.1 \%$ & $8.4 \%$ & \\
& & & & \\
Age & & & & \\
$18-24$ years & $.4 \%$ & $.6 \%$ & $.9 \%$ & \\
$25-34$ years & $4.7 \%$ & $5.0 \%$ & $6.1 \%$ & \\
$34-44$ years & $15.1 \%$ & $12.8 \%$ & $15.2 \%$ & \\
$45-54$ years & $29.9 \%$ & $30.7 \%$ & $30.1 \%$ & \\
$55-64$ years & $30.6 \%$ & $33.6 \%$ & $32.0 \%$ & \\
65 or older & $19.3 \%$ & $17.4 \%$ & $15.8 \%$ & \\
\hline
\end{tabular}

Note: $* * p<.01$ 
Table 3

Travel planning and information search differences between travel purchasing groups

\begin{tabular}{|c|c|c|c|c|}
\hline & Just Hotel & Just Restaurant & Hotel and Restaurant & Chi-Squar \\
\hline \multicolumn{5}{|l|}{ Travel variables } \\
\hline Travel Budget & & & & $294.05 * * *$ \\
\hline$\$ 0-\$ 49$ & $0 \%$ & $3.6 \%$ & $.5 \%$ & \\
\hline$\$ 50-\$ 99$ & $2.4 \%$ & $7.8 \%$ & $1.2 \%$ & \\
\hline$\$ 100-\$ 149$ & $5.2 \%$ & $8.2 \%$ & $2.8 \%$ & \\
\hline$\$ 150-\$ 199$ & $5.0 \%$ & $7.2 \%$ & $3.5 \%$ & \\
\hline$\$ 200-\$ 299$ & $12.7 \%$ & $13.0 \%$ & $8.7 \%$ & \\
\hline$\$ 300-\$ 399$ & $16.1 \%$ & $9.9 \%$ & $12.8 \%$ & \\
\hline$\$ 400-\$ 499$ & $11.1 \%$ & $6.7 \%$ & $8.9 \%$ & \\
\hline$\$ 500-\$ 599$ & $11.8 \%$ & $9.8 \%$ & $10.4 \%$ & \\
\hline$\$ 600-\$ 799$ & $7.4 \%$ & $6.1 \%$ & $10.1 \%$ & \\
\hline$\$ 800-\$ 999$ & $5.9 \%$ & $6.1 \%$ & $8.6 \%$ & \\
\hline$\$ 1,000-\$ 1,199$ & $8.3 \%$ & $5.9 \%$ & $10.0 \%$ & \\
\hline$\$ 1,200-\$ 1,499$ & $4.8 \%$ & $4.4 \%$ & $6.3 \%$ & \\
\hline$\$ 1,500-\$ 1,999$ & $5.2 \%$ & $3.3 \%$ & $5.0 \%$ & \\
\hline$\$ 2,000-\$ 2,499$ & $2.2 \%$ & $3.2 \%$ & $4.5 \%$ & \\
\hline$\$ 2,500-\$ 2,999$ & $.9 \%$ & $.8 \%$ & $1.1 \%$ & \\
\hline$\$ 3,000$ or more & $1.1 \%$ & $3.9 \%$ & $5.7 \%$ & \\
\hline Purpose of trips & & & & $179.89 * * *$ \\
\hline Vacation/Getaway & $61.6 \%$ & $40.6 \%$ & $59.2 \%$ & \\
\hline Special event & $10.7 \%$ & $10.7 \%$ & $9.8 \%$ & \\
\hline Business/Meeting & $3.7 \%$ & $3.5 \%$ & $6.2 \%$ & \\
\hline Visit family/friends & $20.1 \%$ & $35.4 \%$ & $20.7 \%$ & \\
\hline Other & $3.9 \%$ & $9.9 \%$ & $4.2 \%$ & \\
\hline Length of trip & & & & $330.13^{* * *}$ \\
\hline Less than one day & $2.2 \%$ & $15.0 \%$ & $1.6 \%$ & \\
\hline $1-2$ days & $46.4 \%$ & $26.6 \%$ & $34.7 \%$ & \\
\hline $3-4$ days & $33.9 \%$ & $24.7 \%$ & $39.2 \%$ & \\
\hline 5 or more days & $17.5 \%$ & $33.7 \%$ & $24.5 \%$ & \\
\hline Party size & & & & $20.48^{* * *}$ \\
\hline One person & $7.0 \%$ & $11.0 \%$ & $7.5 \%$ & \\
\hline Two persons & $50.4 \%$ & $51.8 \%$ & $50.8 \%$ & \\
\hline $3-5$ persons & $37.1 \%$ & $31.2 \%$ & $34.4 \%$ & \\
\hline 6 or more persons & $5.5 \%$ & $6.0 \%$ & $7.3 \%$ & \\
\hline
\end{tabular}

Information Search

Access Website

$66.1 \% \quad 65.6 \%$

$77.5 \%$

$53.68^{* * * *}$

Mean

F-value

Usage of Websita

$4.32 \quad 4.26^{\mathrm{b}}$

$4.35^{\mathrm{b}}$

$3.21 *$

Note: $\mathrm{a}=$ ANOVA was used to compare the mean differences between travel groups; ${ }^{*} p<.05 ; * * * p<.001$ 